\title{
Study of the Incidence of Some Chronic Diseases Among patients with Long-term Physical Disabilities
}

\author{
Sevdalina Todorova*(i) \\ Department of Internal Diseases and General Medicine, Faculty of Medicine, Trakia University, Stara Zagora, Bulgaria
}

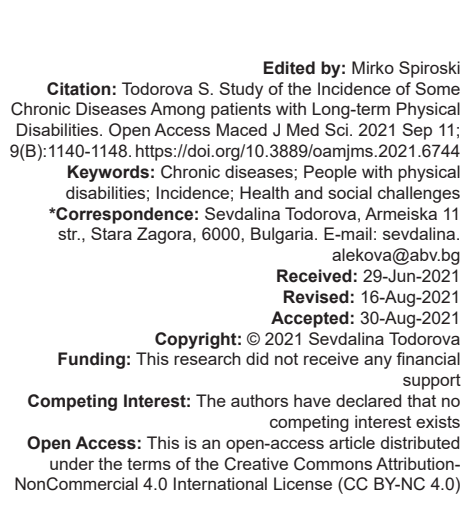

\section{Introduction}

As the population ages, many people are growing older with physical disabilities they were either born with or acquired [1]. The data from the World Health Organization has shown that people with disabilities make up at least $10 \%$ of the population [2]. Further, the cumulative effects of living with a disability condition for many years contribute to premature declines in health according to many researchers [3], [4], [5]. Older adults with physical disabilities may have an even higher risk of health problems than their peers without disabilities for various reasons noted by Campbell and Putnam. The processes of ageing and growing older in patients with physical disabilities are associated with the rise in the prevalence of socially significant diseases with a chronic course and combinations of chronic conditions or so-called multiple chronic conditions. Chronic conditions can be defined as the conditions with nonself-limited and long-term nature. They are associated with persistent and recurring health problems and activity limitations, which are requiring ongoing medical attention [6], [7]. Multiple chronic conditions increase the risk of repeat hospitalizations and receiving conflicting advice from physicians and other health-care providers. They also contribute to frailty, functional restrictions, and aggravating impairments, which further complicate access to healthcare, interfere with self-management, and necessitate reliance on caregivers [1], [8].

\section{Goal}

To date there are no Bulgarian publications to present verified information on the prevalence of chronic diseases among the adults with physical disabilities, as well as research articles on health problems and existing barriers in providing effective medical care for these patients. In addition, the number of such studies worldwide is significantly small. Therefore, the objectives of the study were to determine the incidence of some chronic diseases among the elderly and adults with acquired and congenital physical disabilities and to indicate health and social challenges that people with physical disabilities have to face in their daily lives. 


\section{Materials and Methods}

\section{Study design}

When choosing the methodology for conducting the study the nature of the set goals was taken into account. Two methods were used in the study - descriptive cross-sectional analysis and content analysis. study were:

Main criteria for inclusion of individuals in the

- $\quad$ Persons over 18 years

- $\quad$ Adults and elderly people with physical disabilities, who must be accommodated in a social home

- $\quad$ Presence of congenital or acquired physical disabilities

- $\quad$ Presence of diagnosed and proven chronic diseases, which further affect the personal lifestyle

Main criteria for exclusion of persons in the survey were:

- Individuals under 18 years

- Persons who are not accommodated in the social home

- Lack of congenital or acquired physical disabilities

- $\quad$ Lack of chronic conditions.

\section{Study setting}

The research was conducted at Bulgarian home for adults and elderly people with physical disabilities in Stara Zagora for the period from February 2017 to March 2018.

\section{Sample size and subjects of the study}

The convenience sample includes individuals, which is accommodated in the home for adults and elderly people with physical disabilities. The study was conducted among 179 people with congenital and acquired physical disabilities from the home. The number of women who participated in the study was $104(58.10 \%)$ and the number of men - $75(41.89 \%)$. $149(83.24 \%)$ of the respondents were over 51 years of age and $46(30 \%)$ of them were over 70 years old. Most of them live in a double room with a toilet and a bathroom. The number of married couples staying in the home is relatively small. Most of them are wheelchair users and they need continuous assistance in carrying out their daily activities and those related to maintaining personal hygiene. Major causes of physical disability among participants are congenital diseases and anomalies, pre-existing ischemic or hemorrhagic cerebral infarction, fracture of bones and traumas and some permanent movement disorders that appear in early childhood such as cerebral palsy.

\section{Sampling methods} interview

Descriptive analysis - the semi-structured

The study was conducted in a social home for the elderly and adult with physical disabilities, with the applied method of direct individual survey, done voluntarily with guaranteed confidentiality, respect for personal autonomy, and human dignity. The survey includes questions about demographic characteristics of respondents - age, sex, type of disability, economic status, questions about their lifestyle and access to health services, and self-reported diagnosis of the presence of chronic conditions. Non-directive, openended questions were used, which allowed to examine in depth the position of the respondents about their health and social status, and especially the challenges associated with providing of healthcare, which they face in their lifetime. The aim of the interviews was to let the participants to express their perceptions and situations in their own words.

Content analysis - collection and analysis of the content of available medical documents

Itwas conducted on the available documentation for the health status of each user, which includes a personal health record/personal health card, medical documents presenting consultations with specialists and prescribed medication therapies, individual plans for health, and social care. This additional survey method helped to verify the information about the frequency of chronic diseases and multiple chronic conditions among people with physical disabilities.

\section{Data analysis technique}

The data analysis followed the main steps - reading and examining the transcripts; extracting the key words from the transcripts and sorting them into categories; re-reading the transcripts; and systematic examining the categories and defining the concepts summarizing the material.

The collected information was processed using the statistical software - IBM SPSS Statistics 19.0. Statistical analyses, for example, Mean, Standard deviation, Mode, Variance, S.E. mean, Maximum, Minimum, Range, and Skewness were performed to explore the study population and the data. Cross-tabulation and $\mathrm{X} 2$ were used to examine the relationships between demographic variables, type of chronic disease, and type of acquired or congenital physical injuries. $p<0.05$ was required for statistical significance. 


\section{Ethical considerations}

Ethical issues (including plagiarism, informed consent, misconduct, data fabrication and/orfalsification, double publication and/or submission, redundancy, etc.) have been completely observed by the author. The interviewed adults and elderly with physical disabilities were treated according to the Helsinki Declaration of biomedical ethics. Informed consent was obtained from each interviewed respondent after proper orientation regarding the goals of the survey. The study was approved by the Stara Zagora Municipality's ethics commission and Public health department council staff.

\section{Study limitations}

Limitations of the research that should be mentioned are mainly related to the lack of previous Bulgarian verified research studies on the topic, which can serve as an important opportunity to identify new gaps in the scientific literature and the need for further expanded and in-depth research. Self-reported data are also associated with a risk of potential sources of bias, especially in the application of a semi-structured interview as a research method. However, the trend of raised incidence of chronic diseases among patients with long-term physical disabilities and the presence of health and social challenges that affect their quality of life are conspicuous and this result is to provide valuable information for the health status in disabled persons from social homes.

\section{Results}

The home for adults and elderly people with physical disabilities in Stara Zagora has been in operation since 1976. It accommodates adults after 18 years of age with physical disabilities for the short- and long-term care, as well as for those with a permanent disability over 70 percentages. The accommodation is provided by the social assistance agency in Stara Zagora. This is the largest social home of its kind on the Balkan Peninsula. The capacity of the home is for 211 people, of whom 181 people are long-term residents, and 30 people, who are temporarily accommodated for rehabilitation procedures within 3 months. The social home's staff consists of medical physicians, psychologist, social work specialists, occupational therapists, rehabilitators, and nurses. The team of specialists provides 24-h full medical, domestic, and social services for those with severe physical disabilities. The multidisciplinary team of medical specialists, which have been established in the social home for adults with physical disabilities prepare an individual plan after an assessment of the specific needs of the persons using the social and healthcare services, which is evaluated and updated, if necessary, every 6 months (written social and healthcare plan). Residents with physical disabilities also have to be accurately assessed in terms of their health status. Further, according to The Health Insurance Act and The National Framework Agreement in the Republic of Bulgaria, the health status of each accommodated user is monitored by a general practitioner [9], [10]. Three general practitioners provide primary healthcare for residents with physical disabilities in the home. As mentioned, two medics care for accommodated people in the home and collaborate with their general physicians.

The chronic health problems are fairly common among people with physical disabilities, who are accommodated in the social home (84.91\%). Most of the users $(69.27 \%)$ have at more than two chronic conditions by the time of the survey which is illustrated in Table 1. The most common chronic condition is arterial hypertension - 85 (55.92\%) of the total number of disabled people with diagnosed and proven chronic diseases, followed by chronic diseases of the digestive system - 45 (29.60\%) and chronic diseases of the urinary system - 39 (25.65\%). Socially significant diseases such as diabetes mellitus type II - 24 (15.78\%), chronic diseases of the pulmonary system - 31 (20.39\%), and arthritis and degenerative joints diseases - 32 (21.05\%) have been identified among a smaller percentage of accommodated adults with physical disabilities. Only $9-(5.92 \%)$ of the users have anemic syndrome at the time of the study. Late midlife is a riskier time for the onset of new health problems, which are often associated with chronicity and complications. People with physical disabilities in the mid-50s and early 60 s are more likely to develop diabetes mellitus type II, ischemic heart diseases, chronic kidney diseases, neoplasia than younger ones. At the time of our research, it was detected that high blood pressure was diagnosed amongst all users who suffered from cardiovascular accidents. Overweight, obesity, and immobilization caused are risk factors for developing cardiovascular diseases, diabetes mellitus type II, osteoarthritis, and musculoskeletal diseases. Timely preventative screening to identify lifestyle risk factors would be useful for effective treatment and delay the progressive course of chronic diseases.

The results of the individual interviews with the participants in the study are summarized in Table 2. A significant number of respondents shared, that they continue to experience difficulties in accessing healthcare. To manage multiple chronic conditions, participants desired access to appropriate and welltimed healthcare. Some of them explained situations of frequent symptomatic manifestations of complicated chronic conditions requiring frequent hospital stays, as well as cases of late-diagnosed chronic disease or exacerbation of an existing chronic disease that led to prolonged hospitalization. Adequate access to quality medical services is a necessary and important factor for successful ageing of people with physical disabilities. Most of the surveyed people reported barriers and challenges associated with accessing healthcare. These 
Table 1: Characteristics of the sample

\begin{tabular}{ll}
\hline Selected demographics of focus group patients with physical & $\mathrm{n} \%$ \\
disabilities & \\
\hline Gender & $75(41.89 \%)$ \\
$\quad$ Male & $104(58.10 \%)$ \\
Female & \\
Age & $30(16.75 \%)$ \\
$\quad<50$ years & $60(33.51 \%)$ \\
$51-60$ years & $43(24.02 \%)$ \\
$61-70$ years & $46(25.69 \%)$ \\
$>71$ years & $152(84.91 \%)$ \\
Presence of chronic diseases & \\
$\quad$ Total number of disabled people with diagnosed and & $28(18.42 \%)$ \\
proven chronic diseases & \\
$\quad$ Total number of disabled people with one diagnosed & $124(69.27 \%)$ \\
and proven chronic disease & \\
Total number of disabled people with two or more & $27(15.08 \%)$ \\
diagnosed and proven chronic diseases & \\
$\quad$ Total number of disabled people without diagnosed & \\
and proven chronic diseases & \\
Prevalence of diagnosed and proven chronic diseases among patients & with physical \\
disabilities & \\
$\quad$ Arterial hypertension & $85(55.92 \%)$ \\
Chronic diseases of the digestive system & $45(29.60 \%)$ \\
Chronic diseases of the urinary system & $39(25.65 \%)$ \\
Arthritis and degenerative joint diseases & $32(21.05 \%)$ \\
Chronic diseases of the pulmonary system & $31(20.39 \%)$ \\
Diabetes mellitus type II & $24(15.78 \%)$ \\
\hline
\end{tabular}

include physical and transportation barriers (89.94\% of respondents), financial difficulties in providing the necessary medicines (49.16\% of respondents), limited access to assistive technology and equipment (15.08\% of respondents), delayed or late consultation with a specialist $(34.63 \%$ of respondents), physical inaccessibility or significant difficulties, and obstacles to examination rooms and offices with diagnostic medical equipment (32.40\% of respondents). Some of the respondents discussed further barriers such as disrespectful behavior and poor attitudes $(21.78 \%$ of respondents), a lack of knowledge about disabilities or direct refusal for consultation and physical examination among medical providers (18.99\% of respondents). The complex interaction of these medical, social and lifestyle factors, their timing and impact the developmental life course, represent the most important prerequisites for the early onset of chronic conditions and they create an especially challenging environment for successful aging.

Table 2: Specific social and health care challenges for the sample

\begin{tabular}{ll}
\hline $\begin{array}{l}\text { Barriers and challenges associated with providing of health care } \\
\text { for patients with physical disabilities }\end{array}$ & $\mathrm{n} \%$ \\
\hline $\begin{array}{l}\text { Financial difficulties in providing the necessary medicines } \\
\text { Physical and transportation barriers }\end{array}$ & $88(49.16 \%)$ \\
$\begin{array}{l}\text { Limited access to assistive technology and equipment } \\
\text { Delayed or late consultation with a specialist physical inaccessibility }\end{array}$ & $27(15.94 \%)$ \\
$\begin{array}{l}\text { or significant } \\
\text { Difficulties and obstacles to examination rooms and offices with }\end{array}$ & $58(34.63 \%)$ \\
$\begin{array}{l}\text { diagnostic medical equipment } \\
\text { Direct refusal for consultation and physical examination from health }\end{array}$ & $34(18.99 \%)$ \\
$\begin{array}{l}\text { care providers } \\
\text { Disrespectful behavior and negative attitude of health care providers }\end{array}$ & $39(21.78 \%)$ \\
\hline
\end{tabular}

\section{Discussion}

Disability is part of the human condition. There is no one, unique, and agreed explanation of disability and each country uses a different definition which may cause inequalities for some groups. World health organization's International Classification of Functioning, Disability and Health defines disability as "the negative aspects of the interaction between an individual with a health condition and that individual's contextual factors" [11]. The United Nations Convention on the Rights of Persons with Disabilities provides that "Persons with disabilities include those who have long-term physical, mental, intellectual or sensory impairments which in interaction with various barriers may hinder their full and effective participation in society on an equal basis with others." Disability is therefore understood as the result of the interaction between the individual's impairment and the social, environmental, and attitudinal barriers created by society [12]. According to the European Economic and Social Committee, "the people with disabilities represent about $16 \%$ of the European Union (EU) population, that is, 80 million people. They also represent one-sixth of the working people in the EU and $75 \%$ of them are people who probably need intensive support" [13], [14]. In this regard, every European country provides social and healthcare for people with long-term disabilities or seriously ill people, who live alone, with programs for longterm care. In Bulgaria, the programs for long-term care include providing a personal assistant, social assistant, public canteens, community-based social services and specialized institution - such as old people's homes, homes for people with a physical disability, and homes for people with mental disorders [15]. The social services in specialized institutions are only provided after having exhausted the options for providing social services in the community. The role of Bulgaria's specialized institutions includes to provide suitably furnished and equipped accommodation, rooms for dining and social contacts, healthy and nutritious food including dietary food, depending on the health, and personal preferences of the residents. Furthermore, they assist in the provision of medicine, administration of specialized medical care, assisting to access various administrative services, organizing joint events with other specialized bodies, excursions, and celebrations of personal and national festivities. Furthermore, they provide information on the legislation regulating the social services, the rights and obligations of the residents [15], [16], [17]. Despite the existing health and social care provided by the state specialized institutions in Bulgaria and countries around the world, the statistics indicate that individuals with long-term disabilities are subject to poorer health management than individuals without disabilities, which increases their risk of developing more health problems and early death [18], [19]. People with disabilities are more vulnerable to preventable secondary diseases, comorbidities, untreated mental health statuses, poor oral health, and high obesity rates [20]. This also includes earlier onset of chronic medical conditions as well as development and progression of accompanying complications, which compared with adults without disabilities, are more severe, occur sooner, and stay elevated from midlife into older age [3], [5], [20]. The 
present study, which is based on a sample of respondents living in one of the largest European social homes for adults with physical disabilities, found a significant manifestation of a combination of more than two chronic non-communicable diseases, defined as polymorbidity. Non-communicable chronic conditions are among the most common and costly of all health problems and they have a significant impact on disability status.

The research has shown that nearly half of the residents have long-standing arterial hypertension, which is controlled only by daily drug therapy without reducing harmful habits such as increased consumption of alcohol, cigarettes, caffeine, and consumption of saturated and trans fats. Arterial hypertension is an accompanying disease in all patients with physical disabilities who have suffered from an ischemic or hemorrhagic stroke or acute coronary syndrome. Strokes usually cause brain damage which may can affect language skills, mental ability, or physical activity depending on the severity of the structural lesion. In most cases disabilities after stroke lead to the inability to independently perform activities of daily living such as bathing, dressing, eating, grooming, working, homemaking, and cleaning after defecation. Furthermore, functional disorders in long-term are reason for helplessness, deterioration in quality of life of stroke patients, maladjustment in social relationships, and economic difficulties. Approximately one-fifth of the residents with physical disabilities have diabetes mellitus type $\mathrm{II}$, which is treated with tablets, or they have undergone conventional or intensifying insulin therapy. Some of them have micro and macrovascular complications, which include mainly diabetic polyneuropathy, nephropathy, retinopathy, and ischemic heart disease. In most of the respondents who are diagnosed with diabetes mellitus type 2, also have arterial hypertension, which determines the timing of the onset of early manifestation of tissue and organ damage. The combination of these two diseases leads to a sharp deterioration in a patient's prognosis. They are a major cause of the development of chronic kidney disease and the onset of renal failure, or so-called "silent epidemic." The progression of chronic kidney disease and reduced glomerular filtration are associated with accelerating the processes of vascular damage - atherosclerosis and arteriosclerosis, and their inevitable multi-organ involvement.

The most common urogenital conditions among the respondents detected in the present study are chronic pyelonephritis, generally the obstructive type and unilateral or bilateral nephrolithiasis. The contributing factors of increasing urinary stone disease prevalence include changes in body habitus, fluid status, dietary habits, climate, and the environment [21]. Medical conditions that raise the risk of nephrolithiasis involve primary hyperparathyroidism, obesity, diabetes mellitus, and gout [22], [23], [24], [25], [26], [27]. Urinary stone disease is also associated with other common conditions, such as atherosclerosis, arterial hypertension, chronic kidney disease, and low bone mineral density. The indicated predisposing factors are also found in the respondents suffering from urolithiasis. Even though it is uncertain whether these associations are causal or caused by shared risk factors, a symptomatic stone event heralds future morbidity [21]. Pyelonephritis, an another kidney disease with a high prevalence in the sample is a frequent cause of hospitalization and a major reason of increased morbidity and mortality in older frail patients [28]. Older people are at greater risk for developing pyelonephritis due to poor immunity, higher colonization rates with Gram-negative organisms, multiple comorbidities, and structural changes such as benign prostatic hypertrophy in males, atrophic vaginitis in females, and increased post void residual urine in older people [29]. According to some scientific studies, a higher incidence of bacteriuria and urinary tract infection is observed in elderly patients in longterm care facilities [30], [31] [32], [33]. The conducted research has shown that the home is inhabited by people with disabilities who have an indwelling urethral catheter, which is associated with a higher risk of developing an infection of the urinary tract or complications such as obstruction, incorrect positioning, malposition of the catheter, and trauma of soft-tissue during catheterization. In addition, urinary catheterization disrupts patient defense mechanisms, granting bacteria easier access to the bladder and subsequent ascending contamination [30]. Catheter encrustations can also obstruct urine flow, promoting urine stagnation and bacterial replication [34]. Unfortunately, the complexity of the diagnosis of urinary tract infections, the increasing bacterial resistance to antimicrobials and the inappropriate use of antibiotics continues to be described in long-term care facilities [30]. This determines application of a diagnostic algorithm designed for medical staff to use, which emphasizes close monitoring and early intervention [35].

Chronic diseases of the respiratory system, which are diagnosed in a small part of the study group, include mainly chronic obstructive pulmonary disease in the form of chronic bronchitis, emphysema or mixed variant and bronchial asthma. Chronic obstructive pulmonary disease is characterized by high symptom burden, healthcare utilization, mortality, and unmetneeds of both patients and their caregivers [36]. Along with the inhalation of cigarette smoke or noxious particles, risk factors include age, gender, socioeconomic status, and a history of respiratory infections. These contributing factors for the development of chronic obstructive pulmonary disease were also found among the respondents. Chronic obstructive pulmonary disease is nowadays recognized as a multicomponent disease, despite being defined by the presence of persistent airflow limitation [37]. The disease also affects systems and organs outside the lungs for example, weight loss, 
decreased muscle strength and muscle dysfunction, manifested cardiovascular disease [38]. The treatment of the older patient with chronic obstructive pulmonary disease is highly challenging [39]. Development of non-respiratory impairment and functional limitations, which reflect the systemic nature of the disease, are critical determinants of disablement [40]. Although Chronic obstructive pulmonary disease is a major cause of respiratory failure and dyspnea in the elderly, multiple other disease entities, including heart failure, pulmonary embolism, medication effects, and other conditions, including deconditioning and malnutrition may exacerbate the symptoms [36]. The frequent coexistence of comorbid conditions in older patients, which are higher in number and different than those detected in younger asthmatics, may also complicate the management of asthma [41]. Bronchial asthma is often triggered by environmental factors such as pollen, animal dander, dust, or smoke. Risk factors for late-onset asthma include weight gain, obesity, smoking, rhinitis symptoms, chronic sinus symptoms, viral infections, and new habitual snoring [42], [43]. A similar etiology for the development of bronchial asthma has been reported in the medical records of people with physical disabilities suffering from this disease. The care of asthmatics is addressed to the domains - comorbidities and polypharmacotherapy, which can influence the metabolism and excretion of respiratory drugs, and can negatively impact adherence to and persistence with chronic treatment [41], [44], [45]. In this regard, the management of complex drug regimens in multimorbidity patients is often difficult and the polypharmacy is one of the strongest predictors and the most important risk factor for adverse drug reactions in the elderly [46].

The study has shown a wide variety of gastrointestinal diseases with a chronic course among respondents. The predominant chronic illnesses of the digestive system are chronic gastroduodenitis, gastric ulcer, duodenal ulcer, chronic colitis, and chronic cholecystitis. The percentage of gastrointestinal injuries among individuals determines the second position after arterial hypertension in the present study. Many signs and symptoms of peptic ulcer disease are obscure and confusing. The data from the research have showed that the respondents complain mainly of indigestion or other vague dyspeptic symptoms. The epigastric pain in them varies markedly in nature and intensity. Gastritis and peptic ulcers are caused by many different factors, including medication such as aspirin and nonsteroidal anti-inflammatory drugs, infection with the Helicobacter pylori bacteria, excessive alcohol intake, tobacco use, bile reflux disease, stress, immune disorders, and others. The signs of colitis that are described in the health records of people with disabilities are diarrhea or constipation, intense abdominal pain, swelling of the colon tissue. A major symptom of the surveyed persons with chronic cholecystitis is intermittent pain. In the medical records of symptomatic patients with chronic cholecystitis was found information on the manifestation of dull right upper abdominal pain exacerbated by fatty food intake. This condition usually begins with the formation of gallstones in the gallbladder, which depends on age, gender, genetic predisposion, body mass index, dietary habits, and gallbladder activity. Consumption of fried and spicy foods, refined carbohydrates, trans fats, carbonated beverages, increased alcohol and coffee intake, raised smoking are among the leading harmful behavioral factors for the development of gastrointestinal disorders, to which a large percentage of residents are exposed. Despite providing a balanced and a healthy menu in the home for the adults with physical disabilities, respondents often prefer to buy and consume different variations of "junk food," which is made with unhealthy ingredients.

The number of individuals with physical disabilities who suffer from degenerative changes in the musculoskeletal system is not to be neglected. The hallmark symptom of osteoarthritis, the most common form of arthritis, is pain [47]. It is a frequent companion in the life of the studied contingent with osteoarthritis. With respect to important risk factors for the development of functional limitations and disability among presented sample, the evidence provides strong support for the role of physical impairments along with other predisposing intra-individual factors such as age, overweight and obesity, injury, the previous deformity, structural abnormalities, stroke, psychological and social factors including anxiety, depression, fatigue, health behaviors, and accompanying conditions caused by smoking and alcohol [48]. Extra-individual factors include need for aids and assistance in the form of external supports, therapeutic regimens, medical care, and rehabilitation [49], [50]. Arthritis-disabled persons reported more functional limitations, more buffers as a medical devices and services, assistive equipment, and more barriers to getting around within and outside the social home. Generally, degenerative changes in the musculoskeletal system combined with comorbidity, further impair the lifestyle and determines the lowest levels of physical functioning.

Unfortunately, one of the serious problems characterizing the social assistance system in Bulgaria involves an insufficient number of preventive social and health care services for the elderly and people with disabilities to meet their complex needs [18]. Residents' functional capacities, quality of life, the status of living with a spouse, diagnostic condition, and sex also play the role of barriers in accessing health care for people with a physical disability[51], [52], [53]. As noted by Wong et al. the lack of sufficient financial resources and the inability of people with disabilities to afford out-of-pocket expenses are the highest reason for delaying healthcare. Furthermore, there is now more evidence that the added effects of living with a physical disability for many years contribute significantly to lowering general vitality and the deterioration of health status [4], [54], [55], [56]. The age affects the onset 
and progress of chronic diseases, not only and not so much in itself, but in combination with other factors such as socioeconomic status, lifestyle, type, and dynamics of development of chronic conditions and damages, which are generated by them, adequacy and efficiency of health services and others [57]. Despite the active presence of nursing staff in the home for the elderly with physical disabilities, the study shows an increasing level of multimorbidity correlating with age among respondents. It requires continuous monitoring of accompanying chronic diseases, including an assessment of general health, daily oral medication for most of the residents, intravenous or intramuscular application of drugs, replacement of urethral catheters, treating decubitus ulcers, applying or changing dressings and other outpatient manipulations, planning and conducting consultations with specialists, control of exacerbations episodes in the conditions of the social institution, or hospitalizing the patient according to the severity of manifested symptoms. Besides, in the social category - "persons with disabilities," there is a process of faster, accelerated ageing compared to the category of non-disabled people [58]. This means that the importance of invalidity or physical disability increases as a correlate between higher age and aggravations of old age associated with gradual physical weakness and reduction of the body's vital forces [59]. The presence of chronic diseases in persons with physical disabilities additionally gives rise to restrictions with various types and severity when performing normal activities in private life [58]. Therefore, in the absence of prevention and control, multiple chronic conditions can hinder independence and the health of people with disabilities.

\section{Conclusion}

Chronic diseases are prevalent in adults with a long-term physical disability. Midlife appears to be the target period for the onset of a new illness with a chronic course. In addition, the persons with physical disabilities who have multiple chronic conditions such as heart or lung diseases, kidney diseases, diabetes mellitus, and others are exposed to a higher risk of developing more serious and earlier complications. These chronic diseases contribute to frequent and elevated manifestations of instability, increased functional limitations, and irreversible damages, which further complicate timely access to specialized medical support, significantly interfere with self-management and require constant reliance of health and social services workers. In connection with the current tendency of increasing the prevalence of chronic diseases among adults with physical disabilities, it is necessary to ensure more human and financial resources for the specialized institutions to guarantee the quality of the social and healthcare services for these individuals that complies with the unified governmental standards and criteria. Furthermore, the management of chronic conditions in people with physical disabilities requires continuous collaboration between health and social care providers to adapt prevention, treatment and rehabilitation programs to meet the specific and unique needs of these patients.

\section{Acknowledgments}

I thank the authorities, the mayor of Stara Zagora, General practitioners and personnel of the home for adults and elderly people with physical disabilities, which collaborated in data collection and analysis. Special thanks to all residents who participated in the individual survey and shared their personal opinion.

\section{References}

1. Campbell ML, Putnam M. Reducing the shared burden of chronic conditions among persons aging with disability and older adults in the United States through bridging aging and disability. Healthcare (Basel). 2017;5(3):56. https://doi.org/10.3390/ healthcare 5030056

PMid:28895898

2. Hutton D, World Health Organization. Ageing and Life Course Unit. Older People in Emergencies: Considerations for Action and Policy Development. Geneva: World Health Organization; 2008. Available from: https://www.apps.who.int/ iris/handle/10665/43817. www. apps.who.int

3. Verbrugge LM, Latham K, Clarke PJ. Aging With disability for midlife and older adults. Res Aging. 2017;39(6):741-777. https:// doi.org/10.1177/0164027516681051

PMid:28566012

4. Imai K, Kadowaki T, Aizawa Y. Standardized indices of mortality among persons with spinal cord injury: Accelerated aging process. Ind Health. 2004;42(2):213-8. https://doi.org/10.2486/ indhealth.42.213

PMid:15128171

5. Cook KF, Molton IR, Jensen MP. Fatigue and aging with a disability. Arch Phys Med Rehabil. 2011;92(7):1126-33.

PMid:21704793

6. Goodman RA, Posner SF, Huang ES, Parekh AK, Koh HK. Defining and measuring chronic conditions: Imperatives for research, policy, program, and practice. Prev Chronic Dis. 2013;10:E66. https://doi.org/10.5888/pcd10.120239

PMid:23618546

7. World Health Organization. Global Status Report on NonCommunicable Disease. Geneva, Switzerland: World Health Organization; 2014. Available from: http://www.who.int/nmh/ publications/ncd-status-report-2014/en. [Last accessed on 2017 Jun 16].

8. Ward BW, Schiller JS, Goodman RA. Multiple chronic conditions among US adults: A 2012 update. Prev Chronic Dis. 2014;11:E62. https://doi.org/10.5888/pcd11.130389

PMid:24742395 
9. The Health Insurance Act in the Republic of Bulgaria, Promulgated, SG No. 70/19. 06. 1998, Last Amended and Supplemented 22. 03. 2019; 2019.

10. The National Framework Agreement in the Republic of Bulgaria, Promulgated, SG No. 28/29. 03. 2018, Last Amended and Supplemented 28. 06. 2019; 2019.

11. Sousa RM, Ferri CP, Acosta D, Albanese E, Guerra M, Huang $\mathrm{Y}$, et al. Contribution of chronic diseases to disability in elderly people in countries with low and middle incomes: A 10/66 Dementia Research Group population-based survey. Lancet. 2009;374(9704):1821-30. https://doi.org/10.1016/ s0140-6736(09)61829-8 PMid: 19944863

12. The United Nations. "Convention on the Rights of Persons with Disabilities Treaty Series". Vol. 2515. The United Nations; 2006. p. 3.

13. European Disability Strategy (2010-2020). Opinion of the Section for Employment, Social Affairs and Citizenship on the Communication from the Commission to the European Parliament, the Council, the European Economic and Social Committee and the Committee of the Regions European Disability Strategy 2010-2020: A Renewed Commitment to a Barrier-Free Europe, Brussel; 2011. https://doi. org/10.5235/219174411799494765

14. Dimova M, Milcheva $H$, Andova A. Training of Geriatric Specialists for Building of Communication Skills for Work with Elderly People with Disabilities. CBU International Conference on Innovations in Science and Education, Prague, Czech Republic; 2016. p. 773-6. https://doi.org/10.12955/cbup.v4.848

15. European Commission. Employment, Social Affairs and Inclusion. Available from: https://www.ec.europa.eu/social. [Last accessed on 2021 Apr 15].

16. Bulgarian Social Assistance Act, Promulgated, SG No. 56/19.05.1998, Effective 28.11.2014 Last Amended and Supplemented 30.04. 2019; 2019

17. Rules for the Implementation of the Social Assistance Act in Bulgaria, Promulgated, SG No. 113/11.11.1998, Last Amended and Supplemented 16.08.2019; 2019.

18. National Strategy for Long Term Care in the Republic of Bulgaria; 2014-2020. p. 11-4.

19. Kim YE, Lee YR, Yoon SJ, Kim YA, Oh IH. Years of life lost due to premature death in people with disabilities in Korea: The Korean national burden of disease study framework. J Korean Med Sci. 2019;34(2):e22. https://doi.org/10.3346/jkms.2019.34. e22

\section{PMid:30636948}

20. Kinne S. Distribution of secondary medical problems, impairments, and participation limitations among adults with disabilities and their relationship to health and other outcomes. Disabil Health J. 2008;1(1):42-50. https://doi.org/10.1016/j. dhjo.2007.11.006

PMid:21122710

21. Scales CD Jr., Tasian GE, Schwaderer AL, Goldfarb DS, Star RA, Kirkali Z. Urinary stone disease: Advancing knowledge, patient care, and population health. Clin J Am Soc Nephrol. 2016;11(7):1305-12. https://doi.org/10.2215/cjn.13251215 PMid:26964844

22. Hoff LS, Goldenstein-Schainberg C, Fuller R. Nephrolithiasis in gout: Prevalence and characteristics of Brazilian patients. Adv Rheumatol. 2020;60:2. https://doi.org/10.1186/ s42358-019-0106-4

23. Rejnmark L, Vestergaard P, Mosekilde L. Nephrolithiasis and renal calcifications in primary hyperparathyroidism. J Clin Endocrinol Metab. 2011;96(8):2377-85. https://doi.org/10.1210/ jc.2011-0569

PMid:21646371
24. Ejlsmark-Svensson H, Bislev LS, Rolighed L, Sikjaer T, Rejnmark L. Predictors of renal function and calcifications in primary hyperparathyroidism: A nested case-control study. J Clin Endocrinol Metab. 2018;103(9):3574-83. https://doi. org/10.1210/jc.2018-00923

\section{PMid:29955845}

25. Poore W, Boyd CJ, Singh NP, Wood K, Gower B, Assimos DG Obesity and its impact on kidney stone formation. Rev Urol. 2020;22(1):17-23.

PMid:32523467

26. Nerli R, Jali M, Guntaka AK, Patne P, Patil S, Hiremath MB Type 2 diabetes mellitus and renal stones. Adv Biomed Res. 2015;4:180.

PMid:26605219

27. Assimos DG. Diabetes mellitus and kidney stone formation. Rev Urol. 2006;8(1):44

PMid: 16985563

28. Ramakrishnan K, Scheid DC. Diagnosis and management of acute pyelonephritis in adults. Am Family Physician. 2005;71(5):933-42.

PMid: 15768623

29. Gopal GK, Wilson BP, Viggeswarpu S, Sathyendra S, lyyadurai R, Visvanathan $\mathrm{R}$, et al. Clinical profile and predictors of outcomes in older inpatients with pyelonephritis in a tertiary care hospital in Southern India. J Clin Diagn Res. 2015;9(10):OC05-7. https:// doi.org/10.7860/jcdr/2015/15964.6616

PMid:26557554

30. Genao L, Buhr GT. Urinary tract infections in older adults residing in long-term care facilities. Ann Longterm Care. 2012;20(4):33-38.

PMid:23418402

31. Matsumoto T. Urinary tract infections in the elderly. Curr Uro Rep. 2001;2(4):330-3

PMid:12084261

32. Matthews SJ, Lancaster JW. Urinary tract infections in the elderly population. Am J Geriatr Pharmacother. 2011;9(5):286-309.

PMid:21840265

33. Nicolle LE. Urinary tract infections in the elderly. Clin Geriatr Med. 2009;25(3):423-36.

PMid: 19765490

34. Hooton TM, Bradley SF, Cardenas DD, Colgan R, Geerlings SE, Rice JC, et al. Infectious diseases society of America diagnosis, prevention, and treatment of catheter-associated urinary tract infection in adults: 2009 international clinical practice guidelines from the infectious diseases society of America. Clin Infect Dis. 2010;50(5):625-63. https://doi.org/10.1086/650482 PMid:20175247

35. Nicolle LE. Issues in the diagnosis and management of urinary tract infections in the older adult. Curr Transl Geriatr and Exp Gerontol Rep. 2013;28(1):136-42. https://doi.org/10.1007/ s13670-013-0046-5 PMid:24484576

36. Fried TR, Vaz Fragoso CA, Rabow MW. Caring for the older person with chronic obstructive pulmonary disease. JAMA. 2012;308(12):1254-63. https://doi.org/10.1001/ jama.2012.12422

PMid:23011715

37. Franssen FM, Smid DE, Deeg DJ, Huisman M, Poppelaars J, Wouters EF, et al. The physical, mental, and social impact of COPD in a population-based sample: Results from the longitudinal aging study Amsterdam. NPJ Prim Care Respir Med. 2018;28(1):30. https://doi.org/10.1038/s41533-018-0097-3 PMid:30097575

38. Rennard SI, Locantore N, Delafont B, Tal-Singer R, 
Silverman EK, Vestbo $\mathrm{J}$, et al. Identification of five chronic obstructive pulmonary disease subgroups with different prognoses in the ECLIPSE cohort using cluster analysis. Ann Am Thorac Soc. 2015;12(3):303-12. https://doi.org/10.1513/ annalsats.201403-125oc

PMid:25642832

39. Gonzalez-Moro JM, de Lucas Ramos P, Alonso JL, López-Muñiz Ballesteros B, Díaz EA, Ribera X, et al. Impact of COPD severity on physical disability and daily living activities: EDIP-EPOC I and EDIP-EPOC II studies. Int J Clin Pract. 2009;63(5):742-50. https://doi.org/10.1111/j.1742-1241.2009.02040.x

PMid:19392924

40. Eisner MD, Iribarren C, Blanc PD, Yelin EH, Ackerson L, Byl N, et al. Development of disability in chronic obstructive pulmonary disease: beyond lung function. Thorax. 2011;66(2):108-14. https://doi.org/10.1136/thx.2010.137661

PMid:21047868

41. Battaglia S, Benfante A, Spatafora M, Scichilone N. Asthma in the elderly: A different disease? Breathe (Sheff). 2016;12(1):18-28. https://doi.org/10.1183/20734735.002816

PMid:27064568

42. Gonzalez-Diaz SN, Villarreal-Gonzalez RV, De LiraQuezada CE, Guzman-Avilan RI. Outcome measures to be considered on asthma in elderly. Curr Opin Allergy Clin Immunol. 2019;19(3):209-15. https://doi.org/10.1097/ aci.0000000000000525

PMid:30747751

43. Gillman A, Douglass JA. Asthma in the elderly. Asia Pac Allergy. 2012;2(2):101-8.

PMid:22701859

44. Braman SS. Growing old with asthma: What are the changes and challenges? Expert Rev Respir Med. 2010;4(2):239-48. PMid:20406090

45. Wooten JM. Pharmacotherapy considerations in elderly adults. South Med J. 2012;105(8):437-45.

PMid:22864103

46. Onder G, Petrovic M, Tangiisuran B, Meinardi MC, MarkitoNotenboom WP, Somers A, et al. Development and validation of a score to assess risk of adverse drug reactions among in-hospital patients 65 years or older: The GerontoNet ADR risk score. Arch Intern Med. 2010;170(13):1142-8. https://doi. org/10.1001/archinternmed.2010.153

PMid:20625022

47. Neogi T. The epidemiology and impact of pain in osteoarthritis. Osteoarthritis Cartilage. 2013;21(9):1145-53. https://doi. org/10.1016/j.joca.2013.03.018 PMid:23973124

48. McDonough CM, Jette AM. The contribution of osteoarthritis to functional limitations and disability. Clin Geriatr Med. 2010;26(3):387-99.

PMid:20699161
49. Wilkie R, Peat G, Thomas E, Croft P, Wilkie R, Peat G, et al. Factors associated with restricted mobility outside the home in community-dwelling adults ages fifty years and older with knee pain: An example of use of the International classification of functioning to investigate participation restriction. Arthritis Rheum. 2007;57(8):1381-9. https://doi.org/10.1002/art.23083 PMid: 18050177

50. Mottram S, Peat G, Thomas E, Wilkie R, Croft P, Mottram S, et al. Patterns of pain and mobility limitation in older people: Cross-sectional findings from a population survey of 18,497 adults aged 50 years and over. Quality Life Res. 2008;17(4):52939. https://doi.org/10.1007/s11136-008-9324-7

PMid: 18365768

51. Wong JL, Alschuler KN, Mroz TM, Hreha KP, Molton IR. Identification of targets for improving access to care in persons with long term physical disabilities. Disabil Health $\mathrm{J}$. 2019;12(3):366-74. https://doi.org/10.1016/j.dhjo.2019.01.002 PMid:30880008

52. Lundström U, Wahman K, Seiger $\AA$, Gray DB, Isaksson G, Lilja M. Participation in activities and secondary health complications among persons aging with traumatic spinal cord injury. Spinal Cord. 2017;55(4):367-72. https://doi.org/10.1038/sc.2016.153 PMid:27845357

53. Terrill AL, Molton IR, Ehde DM, Amtmann D, Bombardier $\mathrm{CH}$ Smith $\mathrm{AE}$, et al. Resilience, age, and perceived symptoms in persons with long-term physical disabilities. J Health Psychol. 2016;21(5):640-9. https://doi.org/10.1177/1359105314532973 PMid:27165965

54. Amtmann D, Bamer AM, Nery-Hurwit MB, Liljenquist KS, Yorkston K. Factors associated with disease self-efficacy in individuals aging with a disability. Psychol Health Med. 2019;24(10):1171-81. https://doi.org/10.1080/13548506.2019.1 612082 PMid:31033342

55. Terrill AL, Molton IR. Frequency and impact of midlife stressors among men and women with physical disability. Disabil Rehabil. 2019;41(15):1760-7. https://doi.org/10.1080/09638288.2018.14 48466

PMid:29521178

56. Battalio SL, Jensen MP, Molton IR. Secondary health conditions and social role satisfaction in adults with long-term physical disability. Health Psychol. 2019;38(5):445-54. https://doi. org/10.1037/hea0000671 PMid:31045428

57. Ivkov B. Injuries and Disabilities of the Population. The Population of Bulgaria at the Beginning of the $21^{\text {st }}$ Century. Status and Tendencies. Sofia: Al "Prof. Marin Drinov; 2011. p. 339-70.

58. Ivkov B. Analysis of the Needs of People with Disabilities for Social Inclusion through Employment. Part 1, Sofia; 2013. p. 33.

59. Ostrowska A, Sikorska J. Syndrom Niepełnosprawności w Polsce. Warszawa: Bariery Integracji; 1996. 